Nloman 2015, 33(1), 31-42

Revista de Psicologia, Ciències de l'Educació i de l'Esport

ISSN: $1138-3194$

Copyright (C) 2015

www.revistaaloma.net

\title{
Avaluació, diagnòstic i intervenció en la dislèxia
}

\author{
Enriqueta Garriga \& Mireia Sala
}

Universitat Ramon Llull

Rebut: 3-2-2015

Acceptat: 7-4-2015

\section{Avaluació, diagnòstic i intervenció en la dislèxia}

Resum. En els últims anys, l'aprenentatge de la lectura i les seves dificultats ha estat de gran interès per als educadors $i$ investigadors, propiciant una evolució en el coneixement dels processos implícits en el seu aprenentatge. S'ha arribat a un consens ampli i generalitzat sobre què és la dislèxia i sobre les dificultats que presenta per reconèixer que la consciència fonològica és un dels predictors més fiables del mateix trastorn.

A Catalunya, a partir de la LEC (2009), s'han estimulat les actuacions en el sistema educatiu per tal de garantir l'atenció als trastorns d'aprenentatge; en concret, s'ha millorat la formació dels docents i s'han elaborat instruments i materials que facilitin la seva tasca, com ara els protocols de detecció i atenció a l'alumnat amb dislèxia elaborats l'any 2011.El present article se centra en aquest marc i pretén un doble objectiu: (a) orientar i analitzar el procés d'actuació més eficient a l'hora d'avaluar i diagnosticar precoçment la dislèxia, i (b) donar un model perquè, des del marc escolar, es puguin assumir competències i generar procediments per garantir la trajectòria acadèmica dels nens dislèctics $i$ evitar problemes de desajust emocional $i$ social amb el pas del temps.

Paraules clau: dislèxia, consciència fonològica, trastorn d'aprenentatge, comorbiditat

\section{Dyslexia: assessment, diagnosis and intervention}

Summary. In recent years, language teaching and the difficulties that go along with it have been of great interest to educators and researchers, spurring an evolution in the knowledge of the processes involved therein. There is now a far-reaching consensus as to what dyslexia is and the difficulties it provokes, as well as the recognition that phonological awareness is one of the most reliable predictors of the disorder.

Under the 2009 Catalan education law (LEC) there has been an increased emphasis on actions within the education system undertaken with the aim of guaranteeing proper attention to those with learning disorders. Specifically, there has been an improvement in teacher training, as well as the creation of tools and materials that facilitate their work, such as the protocols on detection and assistance to students with dyslexia, drafted in 2011. This article is written within the context of this framework and has two aims: (a) to provide guidance and analysis as to the most efficient course of action for the early assessment and diagnosis of dyslexia, and (b) to offer a model under which schools can take on greater responsibility and generate processes to help guarantee the academic progress of dyslexic children and avoid the problems of emotional and social maladjustment that can come with time.

Keywords: dyslexia, phonological awareness, learning disorder, comorbidity 


\section{Introducció}

Actualment, ensenyar a llegir i a escriure és un dels objectius prioritaris de l'escola i, per tant, ser competent en llengua escrita esdevé essencial per a viure en la nostra societat. Llegir i escriure són dues habilitats estretament relacionades perquè ambdues depenen del desenvolupament de les capacitats de comprensió i expressió oral dels nens i, lingüísticament, són una representació de la llengua oral tant a nivell fonològic com ortogràfic.

En aquest article parlarem sobre un dels trastorns que afecten el procés d'aprenentatge i que es coneix amb el nom de DISLÈXIA. Malgrat les diferents definicions de dislèxia, els experts estan d'acord en dos punts bàsics: d'una banda, que la dislèxia s'identifica amb un trastorn d'aprenentatge de la llengua escrita; en altres paraules, està àmpliament acceptat que la dislèxia existeix. De l'altra, el llarg debat sobre la seva existència ha posat de manifest la necessitat de disposar de professionals competents per a identificar-la precoçment i desenvolupar camins eficaços per a ajudar els alumnes a superar els seus efectes.

En aquest sentit, en tractar-se d'un trastorn d'aprenentatge, el marc fonamental de detecció i d'intervenció és l'escola i això determina el qui, el com i el quan cal dur a terme aquests dos processos. Com la recerca indica, la detecció i la intervenció davant les dificultats en l'aprenentatge de la llengua escrita, han de ser precoces, i les estratègies d'intervenció han de ser incorporades al més aviat possible en les pràctiques escolars per tal d'assegurar l'alfabetització i el progrés de tot l'alumnat. Al mateix temps, és important desenvolupar intervencions d'alta qualitat per a nens amb dislèxia, basades en l'evidència i el rigor científic. Això requereix l'ajut de professionals especialitzats en llenguatge que siguin els responsables del diagnòstic i del tractament més específic. Cal destacar, finalment, que aquest article segueix la mateixa línia conceptual i formal del Protocol de detecció i actuació en la Dislèxia. Àmbit Educatiu. PRODISCAT (CLC, 2011) elaborat en el nostre país per detectar les possibles dificultats en llengua escrita des de l'escola.

\section{Què és la dislèxia}

La International Dyslexia Association descriu la dislèxia com una dificultat específica de l'aprenentatge de la lectura amb un origen neurobiològic que es caracteritza per dificultats en el reconeixement precís i fluid de paraules i per problemes d'ortografia i descodificació.
Aquestes dificultats provenen d'un dèficit en el component fonològic del llenguatge que és inesperat en relació altres habilitats cognitives que es desenvolupen amb normalitat i d'una instrucció lectora a l'aula adequada. Les conseqüències o efectes secundaris es reflecteixen en problemes de comprensió i en el desenvolupament del vocabulari (IDA, 2002; Lyon, Shaywitz \& Shaywitz, 2003).

Seguint Rose (2009), els punts clau que cal tenir en compte quan parlem de dislèxia són aquests:

- Afecta el procés lectoescriptor i estan alterades, fonamentalment, les habilitats de consciència fonològica, memòria verbal i velocitat de processament verbal.

- Es produeix al marge de les habilitats intel-lectuals.

- A l'hora de fer un diagnòstic, és més adequat parlar d'un contínuum de símptomes que d'una categoria concreta i no és clar quins són els límits exactes.

- Les dificultats que solen estar associades a la dislèxia són les següents: alteracions en alguns aspectes del llenguatge, en la coordinació motriu, en el càlcul mental, en la concentració i la planificació; ara bé, cap d'aquestes dificultats no determina una dislèxia.

- Un bon indicador de la gravetat i la persistència de la dislèxia l'obtindrem examinant com l'alumne respon o ha respost a una bona intervenció.

- Segons els estudis més recents en parla anglesa, la prevalença estimada de la dislèxia, tot i que varia segons on es marqui el límit en l'ampli espectre dels símptomes, se situa entre el 4 i el $10 \%$.

- Existeix l'evidència que fills de pares amb dislèxia tenen un alt risc de presentar el mateix trastorn. Tot i això, la investigació sobre la transmissió genètica està oberta.

- Finalment, la dislèxia persisteix durant l'adolescència i en l'edat adulta, però no podem oblidar que la gravetat de les dificultats depèn sovint de la qualitat i la precocitat amb què s'hagi donat suport a l'alumne, tant en l'àmbit familiar com en l'escolar (vegeu Taula 1)

\section{Detecció, identificació, avaluació i diagnòstic}

Si el trastorn de la dislèxia es veu com un contínuum, cal determinar quan i per què un nen es pot considerar que té dislèxia i qui està capacitat per a contribuir a una avaluació que confirmi aquest diagnòstic.

Nivells d'identificació i avaluació:

\section{DETECCIÓ}

2. IDENTIFICACIÓ, AVALUACIÓ I DIAGNÒSTIC

3. AVALUACIÓ GLOBAL I INTERDISCIPLINÀRIA

4. INFORME ESPECIALITZAT

Taula 1. Pronòstic o conseqüències a llarg termini (CLC, 2011)

\begin{tabular}{ll}
\hline Pronòstic positiu & Pronòstic negatiu \\
\hline Quan s'ha produït o hi ha hagut: & Quan s'ha produït o hi ha hagut: \\
- intervenció d'alta qualitat & - problemes fonològics greus \\
- bones habilitats de llenguatge oral & - escassa velocitat de processament \\
- habilitats per a mantenir l'atenció & - pocs recursos compensatoris \\
- bon suport familiar & - dificultats d'aprenentatge associades \\
& - detecció i intervenció tardana \\
& - escassa intervenció docent \\
\hline
\end{tabular}




\section{Detecció}

Els mestres són els primers que poden fer la detecció d'aquest trastorn al més aviat possible per poder intervenir de forma preventiva utilitzant protocols com el PRODISCAT (CLC, 2011). El primer pas per a identificar nens que presenten dificultats en l'aprenentatge de la llengua escrita, incloent-hi la dislèxia, és advertir el seu pobre progrés en comparació amb el desenvolupament dels seus companys, malgrat rebre un ensenyament d'alta qualitat a l'aula. Per tant, cal treballar intensament i de forma sistemàtica a dins de l'aula per assegurar que, durant la segona Etapa d'Infantil i en el Cicle Inicial, s'ensenyin de forma correcta i eficaç totes les habilitats per al reconeixement de paraules $\mathrm{i}$ la comprensió del llenguatge. En el moment en què els mestres adverteixen diferències individuals en la forma i en el ritme d'aprendre de l'infant, cal controlar el progrés, sobretot en els aspectes següents:

- A l'Educació Infantil, a partir del treball de consciència fonològica $(\mathrm{CF})$, iniciant amb ritmes $\mathrm{i}$ rimes, al-literacions, combinació i segmentació d'unitats de la paraula (síl-labes fins a arribar a la discriminació de sons/fonemes).

- A Cicle Inicial amb el reconeixement de lletres (grafies) i amb la combinació i segmentació d'unitats petites en fonemes: Consonant-Vocal (C-V), VocalConsonant (V-C), Consonant-Vocal-Consonant (C$\mathrm{V}-\mathrm{C})$. Tot i tenir en compte que els índexs de progrés dels nens poden variar considerablement en aquestes edats, les observacions de com progressa cada un poden ser de gran utilitat per a identificar de manera precoç les dificultats en el llenguatge oral i escrit. En tot moment i en les diferents àrees, el mestre ha d'observar també el progrés en relació a les àrees de comprensió de llenguatge oral i escrit. A aquestes edats, també és important assegurar-se que l'audició i visió del nen és correcta i ha estat avaluada.

- En finalitzar el Cicle Inicial i durant els Cicles Mitjà i Superior, els mestres han de continuar fent el seguiment i la revisió del progrés dels seus alumnes, conjuntament amb les seves famílies i amb els mateixos alumnes, de cara a detectar les dificultats, la qual cosa pot requerir la intervenció d'un especialista.

- A Secundària, cal que els professors que observin dificultats de lectura i escriptura en els seus alumnes que no hagin estat detectades durant l'etapa de Primària, derivin urgentment aquests nois i noies cap a l'especialista de llenguatge.

Finalment, els mestres han de conèixer alguns indicadors o signes d'alerta que poden ser útils per a poder identificar possibles problemes, molts dels quals estan recollits en el PRODISCAT.

- Etapa Infantil:

- Parla retardada o amb problemes.

- Llenguatge expressiu pobre.

- Poques habilitats per a percebre «rimes».

- Poc interès/Dificultat per a aprendre lletres.

- Cicle Inicial:
- Pobre coneixement de consciència fonològica (CF).

- Escàs coneixement correspondència so-grafia.

- Dishabilitat per al reconeixement de paraules.

- Ortografia idiosincràtica.

- Problemes en la còpia.

- Cicle Mitjà i Superior:

- Lectura lenta.

- Pobra habilitat per a descodificar paraules noves.

- Dificultats en l'ortografia natural i arbitrària.

- Adolescents $i$ adults:

- Pobre fluïdesa lectora.

- Lentitud en escriure.

- Dificultats d'expressió i d'organització en el treball.

\section{Identificació, avaluació i diagnòstic}

El diagnòstic de dislèxia no es pot fer abans dels 7-8 anys (quan acaba el Cicle Inicial a l'etapa de Primària). En aquest moment és quan l'alumnat ha d'haver assolit els processos bàsics de la lectura i de l'escriptura i es considera que aquestes habilitats ja li han de servir com a mitjà per a fer altres aprenentatges curriculars. En cas que l'alumne no hagi aconseguit el nivell de lectura adequat, malgrat tot un esforç previ, el responsable passa a ser el logopeda o psicopedagog amb amplis coneixements de llenguatge. En aquest moment s'inicia el procés d'avaluació que requerirà els passos següents:

1. Fer una entrevista exhaustiva amb els pares per a recollir la història clínica (mèdica, familiar i del desenvolupament).

2. Valorar la història escolar de l'alumne a partir de tota la informació que aporten els mestres.

3. Assegurar-se que no existeixen problemes sensorials $\mathrm{i}$ intel-lectuals que puguin ser la causa dels problemes de llenguatge escrit.

4. Avaluar el llenguatge oral i les habilitats que intervenen en l'aprenentatge del llenguatge escrit.

5. Avaluar quantitativament i qualitativament les dificultats de lectura i escriptura.

Una vegada iniciat el procés diagnòstic, cal basar-se en un sistema de classificació internacional, el qual defineix els criteris per a la identificació d'una possible dislèxia. Els sistemes més acceptats són aquests:

CIE-10 (OMS, 2003), en el qual apareix la categoria F81 de Trastorns específics del desenvolupament de l'aprenentatge escolar:

- Trastorn específic de lectura (F81.0) (equivalent a Dislèxia)

- Trastorn específic de l'ortografia (F81.1) (equivalent a Disortografia)

- Trastorn específic del càlcul (F81.2) (equivalent a Discalcúlia)

- Trastorn mixt del desenvolupament de l'aprenentatge escolar (F81.8)

- Trastorn del desenvolupament de l'aprenentatge escolar sense especificació (F81.9)

DSM-5 (APA, 2013), que inclou el trastorn específic d'aprenentatge dins l'apartat de Trastorns del neurodesenvolupament i defineix els criteris diagnòstics següents: 
A. Dificultat en l'aprenentatge i en «l'ús de les aptituds acadèmiques», evidenciat per la presència de, si més no, un dels símptomes següents que han persistit com a mínim durant 6 mesos, malgrat les intervencions adreçades a resoldre aquests problemes: lectura imprecisa, lenta i amb esforç; dificultats de comprensió lectora; dificultats ortogràfiques; dificultats amb l'expressió escrita; dificultats per a dominar el sentit numèric, les dades numèriques o el càlcul; dificultats amb el raonament matemàtic.

B. Les habilitats acadèmiques afectades estan substancialment per sota de les esperades per l'edat cronològica de la persona i causen una significativa interferència en el rendiment acadèmic o laboral, o en les activitats de la vida quotidiana, que es confirmen per l'administració de mesures estandarditzades i administrades de manera individual i per una avaluació clínica àmplia. Per a les persones de 17 anys o més, una història documentada de dificultats d'aprenentatge pot substituir l'avaluació estandarditzada.

C. Les dificultats d'aprenentatge comencen en l'edat escolar, però poden no manifestar-se completament fins que les demandes de les aptituds acadèmiques afectades superin les capacitats de la persona (p. ex., proves amb temps limitat, lectura o escriptura d'informes complexos i llargs amb una data límit de lliurament o tasques acadèmiques excessivament pesades).

D. Les dificultats d'aprenentatge no s'expliquen per una discapacitat intel-lectual, visual o auditiva no corregida o altres trastorns mentals o neurològics, adversitat psicosocial, falta de competència lingüística o instrucció acadèmica inadequada.

Més enllà d'aquests sistemes de classificació, cal dur a terme una anàlisi exhaustiva de les diferents habilitats que exposem a continuació.

\section{Avaluació de les habilitats lingüistiques relacionades amb la lectura}

Fan referència a les habilitats que impacten en l'aprenentatge de processos essencials de la lectura i de l'escriptura:

- Expressió oral (fluència expressiva, estructures gramaticals, vocabulari, organització del discurs) i comprensió oral (ordres seguides, frases i històries).

- Percepció auditiva, discriminació auditiva, memòria seqüencial auditiva i discriminació fonològica de logotomes.

- Consciència Fonològica.

- Memòria verbal a curt i a llarg termini.

- Velocitat de processament verbal.

- Velocitat de denominació.

- Seqüències verbals automàtiques: dies de la setmana, mesos de l'any, etc.

\section{Avaluació de la lectura}

És important observar en quines paraules el nen troba més dificultats per a llegir. Si les dificultats es troben en paraules desconegudes o noves, pot tractar-se d'una dificultat fonològica $\mathrm{i}$, si observem que les dificultats sorgeixen davant les paraules familiars amb un reconeixement lent de les paraules molt freqüents, interpretaríem que es tracta d'un problema més lèxic.

- Coneixement de l'alfabet.

- Reconeixement de paraules i pseudoparaules.

- Fluïdesa lectora (velocitat, precisió i prosòdia). - La comprensió lectora d'oracions i textos.

\section{Avaluació de l'escriptura}

Ens hem de fixar en les errades que comet l'infant mentre escriu. La majoria de les vegades hi ha una dificultat tant de la ruta fonològica com lèxica, però cal observar quines paraules li costen més. Si li costa sobretot escriure paraules poc familiars, pseudoparaules, paraules noves, canvia sons, fa inversions, addicions o omissions, es tractaria d'una dificultat més de la ruta indirecta o fonològica. Si escriu correctament paraules amb ortografia regular que s'escriuen tal com sonen i s'ajusten a les regles de conversió fonema-grafema però té dificultats en escriure paraules irregulars per no crear una representació ortogràfica tant de paraules d'ortografia arbitrària reglada com no reglada, ens podem trobar davant una dificultat més de la ruta directa o lèxica. Avaluarem:

- Ortografia natural i arbitrària.

- Domini del traç.

- Expressió escrita: gramàtica i puntuació, claredat en l'organització i estructuració del text.

\section{Avaluació de l'aritmètica}

Pel fet que és freqüent que els nens amb dislèxia tinguin un rendiment baix en matemàtiques hem d'avaluar el següent:

- Nocions de quantitat, estimacions i càlculs aproximats.

- Precisió i fluïdesa en el càlcul i automatització de les taules de multiplicar.

- Aptituds espacials, organització del full, sentit de l'orientació, ubicació dels nombres en columnes i geometria.

- Capacitat per a seguir procediments, recordar passos en operacions o problemes, seriacions i comprensió del valor posicional dels nombres.

- Comprensió de conceptes abstractes com ara temps, direcció, distància i mesura.

- Comprensió verbal dels enunciats.

- Atenció, impulsivitat en la resposta, capacitat de planificació i resistència a la fatiga.

\section{Avaluació d'altres habilitats no lingüístiques}

- Percepció i memòria visual.

- Integració i coordinació visuomotriu.

- Orientació espacial.

- Memòria de treball.

- Velocitat de processament.

\section{Avaluació de les aptituds i dels punts forts}

No tots els nens amb dislèxia tenen un talent extraordinari, però cada un d'ells té un potencial únic que 
freqüentment passa desapercebut perquè no sabem com explotar-lo (Wolf, 2008). Per aquest motiu, és tant o més important valorar les habilitats com les dishabilitats i és imprescindible conèixer si l'alumne té aptituds creatives, artístiques, visuals, manipulatives, etc.

\section{Avaluació a través de proves estandarditzades}

Es ressenyen algunes proves estandarditzades que poden ajudar a avaluar algunes de les habilitats esmentades anteriorment:

- WISC IV Escala d'Intel-ligència per a nens (Wechsler, 2005).

- PECO. Prova per a l'avaluació del coneixement fonològic. 3-6 anys (Ramos \& Cuadrado, 2006).

- PROLEC-R. Català. Bateria d'avaluació dels Processos lectors (Cuetos, Rodríguez, Ruano \& Arribas, 2007).

- PROESC. Batería de Evaluación de los Procesos de Escritura (Cuetos, Ramos \& Ruano, 2002).

- ACL. Avaluació de la Comprensió lectora (Català, Català, Molina \& Monclús, 2004).

- PACBAL. Prova d'avaluació dels components bàsics de la lectura (Castells, Font \& Ramon, en premsa).

- T.A.L.E.C. Test d'anàlisis de Lectura i Escriptura en català (Cervera, Toro, Gratacós, de la Osa \& Pons, 1991)

- PPAI. Proves Psicopedagògiques d'aprenentatges instrumentals (Canals, Carbonell, Estaun \& Añaños, 1988).

- DST-J. Test para la detección de la dislexia en niños (Fawcett \& Nicolson, 2010).

- TEDIMATH . Test per al diagnòstic de les competèncias bàsiques en matemàtiques (Grégoire, Noël \& Van Nieuwenhoven, 2005)

- FIGURA DE REY. Test de còpia d'una figura complexa (Rey, 1980).

- Test gestàltic visomotor de BENDER ( Bender, 1955).

\section{Avaluació global i interdisciplinària (comorbiditat)}

Pel fet que la dislèxia és un trastorn d'aprenentatge de base lingüística, el rol del logopeda és fonamental; en alguns casos, però, si hi ha implicats aspectes emocionals, socials, motivacionals, atencionals o de funcions executives, caldrà un abordatge interdisciplinari amb altres especialistes. Així, doncs, encara que la dislèxia a nivell cognitiu parteix d'un dèficit fonològic, és habitual la comorbiditat amb trastorns com ara el TDAH, la Disgrafia, la Discalcúlia, etc.

\section{Informe especialitzat}

La finalitat de l'avaluació és arribar a un diagnòstic, però, sobretot, poder elaborar un perfil individualitzat dels problemes de lectoescriptura que presenta cada alumne per orientar la intervenció (Lara, 2013).

\section{Criteris que cal reflectir en l'informe}

L'informe ha de recollir totes les dades que poden ajudar a demostrar els criteris diagnòstics següents:
- Criteri d'exclusió: En l'informe ha de quedar clar que no s'identifiquen dificultats de tipus cognitiu, sensorial, ambiental o instructiu que expliquin els errors de lectura i escriptura.

- Criteri de discrepància intraindividual: Un rendiment de la lectura i l'escriptura significativament inferior al nivell esperat tenint en compte l'edat, el QI i el seu nivell escolar. Quan una persona presenta dislèxia, s'observa una diferència important entre l'adquisició de les habilitats afectades i l'adquisició de la resta d'habilitats.

- Criteri d'especificitat: Ha de quedar clar que es tracta d'un trastorn específic d'aprenentatge que afecta la lectura i l'escriptura, encara que pot anar acompanyat d'altres trastorns com el TDAH o la Discalcúlia.

- Criteri de cronicitat: No es tracta d'un retard, sinó d'un dèficit persistent al llarg de la vida.

\section{Determinar el subtipus de Dislèxia}

En l'informe també s'hi pot especificar el subtipus de dislèxia i el nivell de severitat en el moment de fer l'exploració:

- Dislèxia fonològica: pròpia de nens amb dificultats per a utilitzar la ruta fonològica en el moment de llegir les paraules, però que tenen un bon funcionament de la ruta lèxica. Els costa la conversió grafemafonema i, per tant, llegir pseudoparaules o paraules poc familiars, però tenen menys problemes per a llegir les paraules freqüents gràcies a la ruta lèxica.

- Dislèxia superficial: pròpia de nens amb dificultats per a utilitzar la ruta lèxica a l'hora de llegir paraules, però tenen un bon funcionament de la ruta fonològica. No reconeixen les paraules globalment, sinó que les descodifiquen i, per tant, també presenten molta lentitud per a llegir les paraules freqüents i familiars.

- Dislèxia mixta: pròpia de nens que presenten dificultats en les dues rutes d'accés al lèxic.

\section{Nivell de severitat de la dislèxia}

- Lleu: s'observen algunes dificultats en les habilitats d'aprenentatge que afecten un o dos àmbits acadèmics, però de gravetat lleu; l'alumne pot compensar-les si rep les adaptacions i els suports adequats, especialment en el període d'escolarització i formació.

- Moderat: s'observen significatives dificultats en les habilitats d'aprenentatge que afecten una o més capacitats acadèmiques, essent poc probable que l'alumne arribi a ser eficaç sense un tractament especialitzat i perllongat en el procés escolar. En aquest cas, seran imprescindibles algunes adaptacions i alguns suports a l'escola i a casa, per poder completar les tasques escolars amb eficàcia i correcció.

- Greu: s'observen severes dificultats en les habilitats d'aprenentatge que afecten diverses capacitats acadèmiques; en aquest cas, és poc probable que l'alumne pugui adquirir aquestes capacitats sense un intens $i$ especialitzat tractament en el període escolar, el qual, 
però, pot no ser suficient per a completar de manera eficaç les tasques.

\section{Terminologia utilitzada en el diagnòstic}

En el moment d'escriure el diagnòstic podem utilitzar la denominació de Dislèxia o trastorn de lectura. Si en l'informe utilitzem el terme Dislèxia per a referir-nos a un patró de lectura caracteritzat per problemes en el reconeixement precís i fluid de les paraules, una pobra descodificació lectora i pobres aptituds per a l'ortografia, és important també especificar les àrees acadèmiques $i$ aptituds alterades (APA, 2013):

315.00 (F81.0) amb dificultats en la lectura

315.2 (F81.81) amb dificultats en l'expressió escrita

315.1 (F81.2) amb dificultats en les matemàtiques

Finalment, cal oferir recomanacions de cara a les acomodacions que s'apliquin a l'aula.

\section{Certificat per a les PAU}

L'alumnat de batxillerat amb acreditació de dislèxia pot sol-licitar d'examinar-se al Tribunal Ordinari Específic (TOE) de les proves d'accés a la universitat (PAU), en els termes que, des del Departament d'Ensenyament, s'estableixen en l'apartat 2.1.2.1., intitulat Certificat de l'alumnat dislèctic per al Tribunal Ordinari Específic (TOE) de les PAU, dins el document «Concreció i desenvolupament del currículum del batxillerat». (Departament d'Ensenyament, 2014).

\section{Intervenció}

Com més estressant sigui l'experiència que viu l'alumne amb l'aprenentatge de la lectura més gran és el risc que eviti de llegir i d'escriure i desenvolupi nivells molt alts d'ansietat en relació a l'escola. Els resultats escolars dels nens amb dislèxia sempre estan per sota dels dels seus companys i, a mesura que passa el temps, la distància entre les trajectòries acadèmiques s'amplia si no es fa un esforç explícit per millorar les seves habilitats de lectura (Francis, Shaywitz, Stuebing, Shaywitz \& Fletcher, 1996).

Les tècniques de neuroimatge han demostrat que els patrons de l'activitat cerebral durant les tasques relacionades amb la lectura difereixen entre els que són bons lectors i els que presenten dislèxia (Shaywitz \& Shaywitz, 2008). En aquest sentit, diferents investigacions han trobat que l'edat en què es duu a terme la intervenció hi juga un paper fonamental; els resultats indiquen que, en nens més petits, després d'una reeducació basada en l'evidència, aconsegueixen patrons d'activació cerebral semblants als observats en nens bon lectors. (Aylward et al., 2003; Meyler, Keller, Cherkassy, Gabrieli, \& Just, 2008; Richards et al., 2007; Shaywitz et al., 2004).

\section{Objectius de la intervenció}

La intervenció pretén dos objectius:
1. Intervenir directament sobre la dificultat per a millorar al màxim les habilitats de l'alumne en llengua escrita.

2. Reduir l'impacte de les dificultats oferint estratègies de suport.

\section{Característiques metodològiques de la intervenció}

La intervenció hauria de reunir les característiques següents:

- Fonètica: Existeix un consens general que els mètodes que desenvolupen la capacitat d'analitzar fonèticament les paraules (consciència fonèmica o fonètica) són els més eficients.

- Sistemàtica: S'ha d'aplicar durant un determinat nombre d'hores i dies a la setmana.

- Estructurada: S'ha d'ensenyar de manera ordenada i contemplar el progrés a través de petits passos.

- Multisensorial: Ha d'integrar de manera activa i interactiva elements visuals, auditius, cinestèsics $i$ tàctils en l'ensenyament i aprenentatge.

- Reiterativa: Ha d'utilitzar de manera sistemàtica el repàs i la repetició en els aprenentatges de cara a assegurar que les noves habilitats s'han automatitzat i consolidat en la memòria.

- Metacognitiva: Ha d'encoratjar l'alumne a pensar sobre quines estratègies $i$ aproximacions poden ser millors per a ell per tal de ser utilitzades en diferents circumstàncies.

- Ha d'estar basada en l'ús d'habilitats compensatòries i en el reforç positiu: cal focalitzar-la en el desenvolupament d'habilitats útils i transferibles, més que en l'excés d'informació, que pot «carregar» innecessàriament la memòria. Cal planificar les activitats pensades perquè els alumnes experimentin l'èxit i coneguin els seus punts forts i els seus punt febles per a poder enfrontar-se millor amb les seves dificultats. - Ha de valorar les conseqüències socials i emocionals associades a les dificultats de la dislèxia, sobretot pel que fa a l'autoestima i a l'autoeficàcia, amb la finalitat d'ajudar a vèncer els obstacles davant la lectura, tals com la baixa confiança i l'ansietat, que apareixen per un fracàs reiterat.

\section{Nivells d'intervenció (Rose, 2009)}

De manera general i davant les dificultats d'aprenentatge dels alumnes dislèctics cal assegurar, des dels centres educatius, els tres nivells d'intervenció:

1r Nivell: Un ensenyament de primera qualitat enriquint els programes de l'aula perquè surtin beneficiats tots els alumnes i, en especial, els que presenten dificultats.

2n Nivell: A més de la intervenció del primer nivell, alguns alumnes requereixen un suport addicional, que es pot rebre en petit grup o a nivell individual.

3r Nivell: Un suport intensiu per a aquells alumnes que requereixen una adaptació personalitzada del programa, el qual s'ha d'adequar a les seves dificultats específiques i greus. 


\section{Periodicitat de la intervenció}

Sempre que es dissenyin programes d'intervenció o suport extraordinari és important fixar la durada, periodicitat i condicions de la intervenció perquè aquesta sigui eficaç. L'avaluació de l'eficàcia de la intervenció cal fer-la en relació als objectius aconseguits basant-se en l'evidència. Atès que no disposem de dades que facin referència a la temporalització de les intervencions fetes en el nostre país, a nivell orientatiu es faciliten les obtingudes per Torgesen, als Estats Units:

Nivell 2 (Torgesen et al., 1999)

- Individual o en petit grup.

- Millor sessions breus però freqüents: sessions de 20 minuts al dia, 4 dies a la setmana fins a un període de 2 anys.

Nivell 3: per a nens amb greus dificultats (Torgesen et al., 2001)

- Programes concrets i revisables.

- Dues sessions de 50 minuts al dia, durant 8 setmanes, o bé, sessions diàries de 30 minuts de 12 a 20 setmanes.

En general, quan les dificultats són relativament lleus, cal esperar un progrés en un espai relativament breu de temps (10 setmanes). Però cal tenir també en compte que hi ha una minoria significativa de nens que no responen bé a una bona intervenció. Aquests nens no han de repetir una i mil vegades els mateixos programes, ja que són poc eficaços per a ells, sinó que, a partir d'una visió més global de les repercussions de les seves necessitats, han de fer una planificació a llarg termini de la intervenció a tots nivells, implementar-la i, en el seu moment, avaluar-la. A continuació presentem els aspectes fonamentals de la intervenció en els diferents nivells.

\section{1r Nivell. Ensenyament bàsic de qualitat a l'aula Responsables: els mestres}

Es tracta d'assegurar, a tots els alumnes, un bon aprenentatge de la llengua escrita des de l'aula, amb programes de qualitat, i que englobi tant la lectura com l'expressió escrita. En aquest cas, caldria fer un treball fonològic sistemàtic i facilitar activitats i experiències per desenvolupar les habilitats de parla i d'escolta i de consciència fonològica, com també treballar de manera sistemàtica l'expressió escrita.

El llenguatge escrit, en els sistemes alfabètics, suposa assimilar un codi que, en automatitzar-lo, ens permet centrar-nos en altres aspectes del mateix text. Aprendre a llegir en aquest sistema, porta implícits una sèrie de processos singulars encaminats a crear vies que permetin convertir el principiant en un lector expert després d'haver aconseguit que assimili i automatitzi el codi alfabètic.

Per això, un dels objectius serà ajudar l'alumne a superar aquests processos amb tota la facilitat i eficàcia. Aquesta condició és clarament insuficient per a ser lector, però si no es compleix, no se'n pot ser. Primer, perquè és l'essència mateixa del sistema alfabètic, i segon, perquè, si un lector ha de dedicar esforços a fer aquest reconeixement primari, segur que no podrà portar a terme les següents operacions més complexes, com ara comprendre el que llegeix.

\section{Aprendre el codi alfabètic}

Per aprendre el codi, cal treballar els processos següents:

1. Consciència fonològica $(\mathrm{CF})$

2. Correspondència so-grafia

3. Fluïdesa lectora

\section{Consciència fonològica}

Hi ha un ampli acord en els resultats de les investigacions que la CF és crítica per a aprendre a llegir i a escriure en llenguatges alfabètics; és a dir, lectors competents de llenguatges alfabètics, tenen invariablement $\mathrm{CF}$, mentre que aquells que presenten un buit en CF també presenten invariablement problemes. En aquesta dimensió és on els nens dislèctics presenten les dificultats i on s'ha de tenir més cura per a assegurar-ne l'aprenentatge. A més, la recerca demostra clarament que la CF pot ser desenvolupada a través d'instruccions i que, fent-ho així, s'acceleren de manera significativa els progressos en lectura i escriptura. Tot això posa de manifest la importància de treballar la CF i reafirma la convicció que un programa d'ensenyament de la lectura especialitzat per als nens amb dislèxia ha d'incorporar un treball en aquesta direcció. Entenem per CF la capacitat de percebre la seqüència de petits sons (els fonemes) que conformen el llenguatge parlat i comprendre que els sons que es poden representar amb les grafies són els mateixos sons de la parla (principi alfabètic). Per tant, el treball de consciència fonològica és auditiu i és previ al de la correspondència so-grafia.

Objectius: desenvolupar progressivament habilitats metafonològiques, és a dir, les capacitats de reflexionar i manipular explícitament la llengua a diferents nivells: - Nivell lèxic: discriminar i separar les paraules dins d'una frase (cap a 3 anys).

- Nivell sil-làbic: reflexionar i manipular síl-labes dins les paraules (cap a 4 anys).

- Nivell fonològic (consciència fonològica): percebre i manipular fonemes dins les paraules (cap a 5 anys).

Activitats: es recomana desenvolupar les que es proposen en el programa consciència fonològica adaptat (Garriga, 2003):

- Jocs d'escoltar. Per entrenar, en els nens, les habilitats d'escolta selectiva dels sons.

- Rimar. Utilitzar la rima per a introduir els nens en els sons de les paraules.

- Paraules i frases. Per a desenvolupar la consciència en els nens sobre el fet que el llenguatge està format per cadenes de paraules.

- Consciència de síl.laba. Per a desenvolupar l'habilitat d'analitzar paraules separades per síl-labes i desenvolupar l'habilitat de sintetitzar paraules a partir de síl-labes separades. 
Tipus d'exercicis:

Comptar-Identificar-Unir-Afegir-Suprimir-Substituir síl-labes

Utilitzar paraules amb estructures sil-làbiques de dificultat progressiva.

Iniciar amb paraules d'estructura:

- CV (consonant-vocal): PA, CA-SA, SA-BA-TA,...

- VC: ÀN-CO-RA, ÓS,...

- CVC: TA-RON-JA, BOM-BE-TA, PAL,...

- CCV: PLO-MA, LLO-RI-GUE-RA, TREN...

- VV: (atenció amb els diftongs; norma arbitrària) NOU, RIU, EU-GA

- Consciència dels fonemes: Per a desenvolupar l'habilitat a l'hora d'analitzar paraules en una seqüència de fonemes separats i desenvolupar l'habilitat de sintetitzar-les a partir de la seqüència de fonemes separats.

\section{Tipus d'exercicis:}

Identificar, Comptar, Afegir, Suprimir, Unir, Substituir fonemes

- L'ordre de dificultat per a percebre els fonemes és des dels més fàcils fins als més difícils:

- Vocàlics

- Consonàntics (nasals- fricatius-oclusius)

- En la posició següent: INICIAL-FINAL-MEDIAL

Periodicitat: aquest treball cal que es dugui a terme durant l'Etapa Infantil; en aquest sentit, és convenient de fer les activitats diàriament, procurant que durin de 15 a 20 minuts .

\section{Correspondència so-grafia}

Ensenyar les relacions existents entre les lletres (grafemes) del llenguatge escrit i els sons concrets (fonemes) del llenguatge parlat.

Objectiu: facilitar als nens la comprensió del principi alfabètic; és a dir, que les lletres, en la paraula escrita (d'esquerra a dreta), representen la seqüència dels fonemes (del primer a l'últim) en la paraula parlada. Una vegada els nens són capaços de dividir les paraules en els diferents sons aïllats, estan preparats per estudiar com aquests sons es representen per lletres (grafies/ grafemes).

Activitats: És un treball de percepció visual i de direccionalitat. El seu aprenentatge es vincula al desenvolupament de la grafomotricitat i del grafisme.

L'aprenentatge s'acostuma a iniciar a P5 i es desenvolupa a 1r de Cicle Inicial.

\section{Fluïdesa lectora}

La fluïdesa lectora o habilitat per llegir de manera ràpida necessita un text. La fluïdesa és un component important de la lectura, ja que fa de pont entre el reconeixement de les paraules i la comprensió. Els lectors menys fluents han de centrar la seva atenció a desxifrar les paraules i això els impedeix concentrar-se en la comprensió del text.

Activitats: Cal tenir en compte que la «fluïdesa» no s'adquireix per assaig-error (fer repetir al nen la lectura incorrecta fins que li surti bé), sinó amb un model correcte o modelatge; per tant, no es tracta de «fer llegir l'alumne, sinó de «llegir amb l'alumne». És imprescindible que el nen segueixi la lectura amb el dit per tal que, amb els ulls, vegi les paraules escrites que sent.

Actualment, estratègies com la lectura alumne-adult (primer llegeix l'adult i després el nen), la lectura conjunta alumne-adult, la lectura conjunta entre dos companys (un millor lector que l'altre), la lectura assistida per magnetòfon (el nen va llegint un text mentre escolta com ho fa un lector fluent pel magnetòfon), els lectors de text, etc., poden ajudar a desenvolupar aquesta habilitat, que farà que els nens agafin gust per la lectura i llegeixin més. La tècnica de reconeixement ràpid de paraules escrites millora la velocitat de reconeixement de paraules aïllades, però no és suficient per a millorar la fluïdesa.

Periodicitat: Quan s'iniciï la lectura, per a millorar la fluïdesa i la comprensió, caldrà dedicar individualment un mínim d'una hora a llegir, repartida en diferents intervals durant el dia.

Barems de valoració: A nivell orientatiu, s'adjunta una taula amb els barems de velocitat lectora recomanada a final de cada curs de Primària.

Cal tenir en compte, però, que l'objectiu de la lectura és comprendre. Per tant, és convenient correlacionar la velocitat amb la comprensió lectora (eficiència lectora). Finalment, recordar que el domini d'aquests processos primaris no és la finalitat de la lectura. Però automatitzar-los és la garantia perquè facilitin i no pertorbin la finalitat principal, és a dir, la comprensió dels textos.

\section{Grafisme}

És un dels aspectes que caldrà ensenyar de manera sistemàtica, estructurada i amb els suports que siguin necessaris. Inicialment, a $\mathrm{P} 3$ es vetllarà perquè els nens treballin diferents habilitats manipulatives que els fa-

Taula 2. Velocitat lectora orientativa a final de cada curs de Primària (IAQSE, 2014)

\begin{tabular}{llllll}
\hline $\mathbf{2 n}$ & $\mathbf{3 r}$ & $\mathbf{4 t}$ & $\mathbf{5 e ̀}$ & 6è & Qualificació \\
\hline+60 & +81 & +107 & +116 & +131 & Bona \\
\hline $47-59$ & $65-80$ & $84-106$ & $86-115$ & $101-130$ & Acceptable \\
\hline $36-46$ & $51-64$ & $65-83$ & $66-85$ & $82-100$ & Baixa \\
\hline-35 & -50 & -64 & -65 & -81 & Molt baixa \\
\hline 50 & 66 & 87 & 92 & 108 & Mitjana \\
\hline
\end{tabular}


cilitin fer la pinça i millorar la coordinació mà-ull. A P4 es recomana iniciar la grafomotricitat, ensenyant els moviments bàsics (traç vertical, horitzontal, inclinat, rodona,...) i vetllant perquè es mantingui una bona postura corporal i una forma adequada d'agafar el llapis. Els«suports» poden ser un paper pautat, amb els marges ben establerts i amb indicacions de la direccionalitat del traç. És bàsic que l'alumne, quan fa el traç, tingui immediatament el feed-back del mestre per si cal refer-lo. Això obliga a treballar amb petits grups d'alumnes, una estona curta de temps, i de forma freqüent.

A finals de P4, durant el P5 i a 1r de Primària, és quan cal treballar el grafisme o el dibuix de les diferents grafies. El suport continua essent el paper pautat -en el cas que s'opti per la «lletra lligada», la millor pauta és la Montessori-, el qual, a mesura que els alumnes vagin adquirint les proporcions de les diferents lletres, s'anirà retirant de mica en mica.. Cal fixar-se en la direccionalitat de les grafies per a evitar moviments innecessaris i traços poc clars. Continua essent imprescindible la correcció immediata i el control periòdic per a evitar grafies poc clares i distorsionades. Sovint, alguns alumnes dislèctics presenten problemes de coordinació motriu i de concentració i atenció. En aquests casos, és especialment important acompanyar-los en aquest aprenentatge per a aconseguir que automatitzin aquests valors al més aviat possible.

\section{Expressió escrita}

Ensenyar a escriure implica els processos següents:

a) Planificar: Adequació i Coherència

b) Redactar: Cohesió - Ortografia - Presentació

c) Revisar i corregir

a) Planificar: Abans d'escriure, és imprescindible «pensar» el que es vol dir, en quin format (tipologia textual) es vol expressar i com cal ordenar la informació. Dos aspectes cal tenir en compte en la planificació del text:

-Adequació: Tot el que s'escriu està relacionat amb el tema.

-Coherència: Destriarar el que és rellevant d'allò que resulta innecessari i ordenar la informació separant-la en els diferents apartats o paràgrafs segons la tipologia del text (descriptiu, narratiu, expositiu, etc).

A partir de 4t de Primària, és convenient ensenyar els alumnes a fer un esborrany amb totes les idees que els vénen al cap i que, posteriorment, hauran d'ordenar separant-les en els diferents apartats del text.

b) Redactar: A l'hora d'escriure el text, s'haurà de tenir present el següent:

-Cohesió: ús correcte dels connectors gramaticals, frases completes i ben relacionades, temps verbals adequats, ús correcte dels pronoms, concordances verbals i nominals... (aplicació progressiva i adequada de les estructures i formes gramaticals apreses en l'àrea de Llengua).

-Ortografia: ús adequat de la puntuació i bona or- tografia (introducció progressiva de l'ortografia arbitrària).

-Presentació: fer una lletra llegible, respectar els marges, fer constar el nom i la data, escriure el títol del text, respectar la separació entre línies, etc.

c) Revisar i corregir

-Ensenyar els alumnes a revisar i a autocorregir els textos sota els cinc aspectes bàsics, essent l'avaluació final la suma de les valoracions de cada apartat. -Corregir només allò que s'ha ensenyat a l'alumne i avaluar-ho en tots els escrits.

-Entendre la correcció com una tècnica didàctica en la qual l'alumne aprèn; cal ser variada i participativa.

-Considerar imprescindible el fet de passar de la correcció del mestre a l'autocorrecció de l'alumne.

-Deixar temps a classe perquè els alumnes puguin corregir els treballs i comentar les correccions.

-Corregir quan l'alumne té fresc el que ha escrit.

- Tenir entrevistes individuals amb l'alumne. Corregir oralment els seus treballs escrits i partir de la seva autoavaluació.

-Donar eines als alumnes perquè es puguin autocorregir: ensenyar-los a manejar i a consultar diccionaris i gramàtiques, llibres de verbs, etc.

-Estimular els alumnes a revisar i a refer els seus textos.

-Augmentar la qualitat de la correcció encara que baixi la quantitat.

-No preocupar-se tant, el mestre, per corregir tots els treballs dels alumnes i assegurar-se, en canvi, un bon nivell de correcció.

Ensenyar a escriure no sols és una competència pròpia de l'àrea de Llengua, sinó també de tots els mestres i professors i de totes les àrees en les quals els alumnes hagin d'escriure. És important que cada escola i cada centre de Secundària (ESO) distribueixi per cursos les tipologies textuals que s'ensenyaran, com també les estructures gramaticals i les normes ortogràfiques que s'exigirà que els alumnes dominin en finalitzar cada nivell. Tots els escrits que es demanen als alumnes -en qualsevol àrea- han de ser corregits i puntuats amb els mateixos criteris.

\section{2n Nivell. Suport addicional}

Responsables: logopedes o psicopedagogs especialitzats en llenguatge

A més de la intervenció del 1r Nivell, alguns alumnes requereixen un suport addicional que poden rebre en petit grup o a nivell individual; la intervenció es basa en programes de classe, però es fan les activitats adequades i adaptades per a assegurar el progrés de l'alumne.

\section{Aprenentatge de la llengua escrita}

- Ensenyar a tenir fluïdesa i precisió: evitar que els alumnes llegeixin en públic en contra de la seva voluntat; ajudar-los perquè la comprensió no estigui compro- 
mesa per la focalització de la seva atenció en la descodificació de les paraules, etc.

- Ensenyar vocabulari tècnic o nou: ajudar els alumnes en la lectura d'un text, anticipant el significat del vocabulari nou; ajustar els textos al rendiment lector de l'alumne, procurant que siguin més breus i amb un vocabulari al seu abast; facilitar el reconeixement del significat de les paraules que llegiran i aprendre a deduir i a entendre les noves paraules.

- Ensenyar a comprendre: Activar els coneixements previs a la lectura; ajudar a fer inferències predictives $i$ interpretatives; utilitzar la conversa sobre la lectura abans de llegir; controlar la comprensió lectora durant tot el procés lector, no solament al final de la lectura.

- Ensenyar l'expressió escrita: Estructurar els textos de diferents tipologies amb esquemes predeterminats; facilitar plantilles amb els connectors, adverbis, adjectius, etc., que poden facilitar l'estructuració dels textos; ensenyar a estructurar els textos amb frases curtes i correctes; no corregir de manera sistemàtica tots els errors ortogràfics de l'escriptura de l'alumne; procurar que els alumnes no hagin de copiar sempre en el full els enunciats del llibre; donar-los un temps addicional per a completar les activitats; permetre la presentació de treballs escrits fets amb l'ordinador i el corrector de textos.

La responsabilitat d'assegurar que l'alumne és capaç de «llegir per a aprendre» no acaba quan deixa l'escola de Primària. És imprescindible que en l'etapa de Secundària es continuiin identificant aquells alumnes que fracassen a causa de les dificultats en la llengua escrita i s'intervingui de manera adequada. A la Gran Bretanya (Brooks, 2007) es constata que hi ha una escassa intervenció especialitzada a nivell de Secundària, malgrat que es consideri que, si els nens rebessin un suport continu, estarien en millors condicions per fer front al pla d'estudis de Secundària.

\section{Altres dificultats en què cal intervenir}

A part de les dificultats descrites anteriorment, sovint n'apareixen d'altres que acompanyen la dislèxia i es poden dividir en dos tipus:

- Les dificultats que es refereixen a problemes en diferents conjunts de processos cognitius o sensorials, com ara dificultats de coordinació motora, d'atenció i de concentració.

- Les dificultats que poden produir-se com a conseqüència del problema principal. Per exemple, els problemes d'organització i planificació personals poden derivar-se d'unes habilitats pobres per a llegir i escriure i d'una escassa memòria a curt termini. De manera similar, pot sorgir una baixa autoestima i una desafecció a partir dels 10-11 anys per l'experiència dels efectes de la dislèxia infantil, incloent-hi la reacció negativa dels altres davant les dificultats d'aquest trastorn.

En aquest sentit, hi ha menys recerca de cara a conèixer l'ampli camp de dificultats associades a la dislèxia, a part de la que fa referència a les dificultats pròpiament de lectura, encara que les persones dislèctiques troben més frustrants i, potencialment, més limitadores les dificultats que s'esdevenen a part de la lectura. Per això la intervenció, sobretot en alumnes més grans, cal que també contempli el desenvolupament de les habilitats d'organització i de tècniques d'estudi, així com l'ús de les tecnologies de la informació i de la comunicació.

L'ús de les TIC: Cal contemplar les TIC com a part de la solució, però no és «la solució». Promoure l'ús de les noves tecnologies sense el suport i orientació per part dels docents perquè siguin funcionals de cara a l'aprenentatge, significa córrer el risc que esdevinguin una rutina més a l'aula, condemnant-les al fracàs. Els beneficis de les TIC fan referència, sobretot, a les oportunitats basades en la modificació i adaptació dels materials d'aprenentatge.

\section{3r Nivell. Suport intensiu}

Responsables: treball conjunt entre els mestres i els especialistes de llenguatge.

És útil per a aquells alumnes que requereixen una adaptació personalitzada del programa, el qual s'ha d'adequar a les seves dificultats específiques i greus. En aquest cas, parlaríem d'un pla individualitzat (PI), que es duria a terme de manera intensiva i durant un temps determinat per facilitar l'accés a la llengua escrita i donar recursos compensatoris a alumnes dislèctics greus o de diagnòstic tardà.

A continuació, només es fa referència a alguns exemples d'adaptacions metodològiques comunes a totes les matèries, perquè es tinguin en compte a l'hora d'elaborar un Pla Individualitzat tant a Primària, com a Secundària i a Batxillerat:

- Disposar de més temps per a fer les proves.

- Alternar proves escrites i orals.

- Donar suport oral a les proves escrites: per part del professorat, llegir en veu alta les instruccions específiques de cada prova i assegurar-se que s'entenen els enunciats.

- No dictar preguntes en els exàmens.

- Procurar no acumular diversos exàmens al mateix dia.

- Valorar més el contingut que la forma.

- No penalitzar, en els exàmens que no són de Llengua, les faltes d'ortografia en la nota final.

- Afavorir exàmens amb enunciats curts.

- Reduir l'extensió de la prova.

- Valorar el treball diari, i no tan sols el resultat de l'examen.

- Fer tutories individualitzades. Reforç positiu.

- Presentar els continguts curriculars amb suports variats: visuals o auditius (esquemes, mapes conceptuals, presentacions en PowerPoint o altres recursos informàtics, documentals, pissarra digital, etc.).

- Fer ús a l'aula de l'ordinador amb softwares específics de lectura i corrector ortogràfic o gravadora. Presentar els treballs fets amb ajuda de l'ordinador.

- Usar la calculadora. 
- No forçar a llegir en veu alta davant del grup (o procurar donar, als alumnes, el text de lectura amb antelació).

- Recomanar la presa d'apunts esquemàtics i l'ús complementari d'apunts de companys.

- Disminuir, en l'avaluació del Català/Castellà/Llengua estrangera, el pes de la penalització de les faltes escrites. (Tot i que es corregeixen totes les faltes d'ortografia i d'estructures gramaticals, no es descompten amb el mateix grau d'exigència i no es comptabilitza la repetició de faltes escrites).

- Avaluar en funció del contingut de l'examen i no en funció de la presentació.

\section{Intervenció amb les famílies}

Finalment, és evident la necessitat i la importància que les famílies i les escoles treballin conjuntament. En la intervenció amb les famílies caldrà tenir en compte el següent:

Assegurar les vies de comunicació.

Informar sobre les mesures d'intervenció programades amb els seus fills o filles (què es farà, quan, amb qui i on) i anar revisant periòdicament i conjuntament el progrés.

Donar importància al fet que l'escola expliqui les seves actuacions i sigui oberta i transparent en les relacions amb les famílies.

Orientar les famílies sobre què poden fer d'acord amb les seves possibilitats.

\section{Conclusions}

Per finalitzar, volem remarcar que, quan parlem de trastorns de l'aprenentatge, és imprescindible partir d'una visió interdisplinària en la qual els docents juguen un paper primordial. La detecció i la intervenció precoç, única garantia per a poder assegurar un bon pronòstic, és competència dels mestres. En el futur, doncs, cal assegurar que la formació, els suports i els recursos tinguin la seva base en l'escola per tal de garantir el progrés i l'èxit de tots els alumnes.

\section{Referències}

American Psychiatric Associations (APA) (2013). Manual diagnóstico y estadístico de los trastornos mentales (DSM-5) (5a edición). Madrid: Editorial Médica Panamericana.

Aylward, E. H., Richards, T. L., Berninger, V. W., Nagy, W. E., Field, K. M., Grimme, A. C., et al. (2003). Instructional treatment associated with changes in brain activation in children with dyslexia. Neurology, 61, 212-219.

Bender, L. (1955). El Test Guestáltico Visomotor. Buenos Aires: Paidós.

Brooks, G. (2007). What Works for pupils with literacy difficulties? London: DCSF.

Castells, M., Font, J. \& Ramon, D. (En premsa). PACBAL. Prova d'avaluació dels components bàsics de la lectura.
Recuperat de, http://www.giee.cat/wp-content/ uploads/2013/12/Avaluacio\%CC\%81-de-la-lectura. pdf 15 de desembre del 2014.

Català, G., Català, M., Molina, E. \& Monclús, R. (2004). Avaluació de la Comprensió lectora. Proves ACL I, Cicle Inicial. Barcelona: Graó.

Canals, R., Carbonell, F., Estaun, S. \& Añaños, E. (1988). PPAI. Proves Psicopedagògiques d'aprenentatges instrumentals. Barcelona: Onda.

Cervera, M., Toro, J., Gratacós, M.I, de la Osa, N. \& Pons, M.D. (1991). T.A.L.E.C. Test d'anàlisis de Lectura i Escriptura en català. Madrid: Visor.

Col.legi de Logopedes de Catalunya. (2011). PRODISCAT Protocol de detecció i actuació en la Dislèxia. Àmbit educatiu. Barcelona: Departament d'Ensenyament de la Generalitat de Catalunya.

Cuetos, F., Ramos J.L. \& Ruano, E. (2002). PROESC. Batería de Evaluación de los Procesos de Escritura. Madrid: TEA.

Cuetos, F., Rodríguez, B., Ruano, E. \& Arribas D. (2007). PROLEC-R. Català. Bateria d'avaluació dels Processos lectors. Madrid: TEA.

Departament d'Ensenyament. (2014). Documents per a l'organització i la gestió dels centres. Concreció i desenvolupament del currículum del batxillerat. Curs 2014-15. Recuperat de, http://educacio.gencat.cat/portal/page/ portal/Educacio/PCentrePrivat/PCPNormativa/PCPDocumentsOrganitzacioGestio/PCPDocumentsActualitat 31 de desembre del 2014.

Fawcett, A.J \& Nicolson, R.I (2010). RDST-J .Test para la detección de la dislexia en niños. Madrid: TEA.

Francis, D. J., Shaywitz, S. E., Stuebing, K. K., Shaywitz, B. A., \& Fletcher, J. M. (1996). Developmental lag versus deficit models of reading disability: A longitudinal, individual growth curves analysis. Journal of Educational Psychology, 88, 3-17.

Garriga, E. (2003). Cal saber parlar per poder llegir? Document elaborat a partir de la llicència d'estudis finançada pel Departament d'Ensenyament de la Generalitat de Catalunya. Recuperat de http://www. xtec.cat/sgfp/llicencies/200203/resums/egarriga. html

Grégoire, J., Noël, M.P \& Van Nieuwenhoven, C. (2005). TEDI-MATH. Test per al diagnòstic de les competències bàsiques en matemàtiques. Madrid: TEA.

Institut d'Avaluació i Qualitat del Sistema Educatiu de les Illes Balears -IAQSE-. (2014). Proves de velocitat lectora. Instruccions $i$ taula de resultats. Recuperat de, http://iaqse.caib.es/proves_velocitat_lectora.htm 15 de desembre del 2014.

International Dyslexia Association (2002). The Nature of Learning Disabilities. Approved 01/07/02. IDA Policy Statements on The Reauthorization of IDEA.

Lara, M. F. (2013). L'avaluació i identificació de les necessitats educatives especials dels nens amb dislèxia. A L. Andreu (Ed.), L'adquisició de la lectura i les seves dificultats (pp. 87-126). Barcelona: UOC.

LEC. Llei d'Educació de Catalunya. Diari Oficial de la Generalitat de Catalunya. DOGC, 5422-16/07/2009. 
Recuperat de http// www.gencat.cat/eadop/imatges/5422/09190005.pdf

Lyon, G.R., Shaywitz, S. \& Shaywitz, B.A. (2003). A definition of dislexia. Annals of Dyslexia, 53, 1-14.

Meyler, A., Keller, T. A., Cherkassky, V. L., Gabrieli, J. D. E., \& Just, M. A. (2008). Modifying the brain activation of poor readers during sentence comprehension with extended remedial instruction: A longitudinal study of neuroplasticity. Neuropsychologia, 46, 2580-2592.

Organización Mundial de la Salud (OMS). (2003). Clasificación estadística internacional de enfermedades y otros problemas de salud CIE-10 Versión en Español. Washington: Organización Panamericana de la Salud.

Ramos, J. L. \& Cuadrado, I. (2006). Prova per a l'avaluació del coneoxement fonològic PECO, 3-6 anys. Madrid: EOS.

Rey, A. (1980). Test de còpia d'una figura complexa. Madrid: TEA.

Richards, T., Berninger, V., Winn, W., Stock, P., Wagner, R., Muse, A., et al. (2007). Functional MRI activation in children with and without dyslexia during pseudoword aural repeat and visual decode: before and after treatment. Neuropsychology, 21(6), 732-741.

Rose, J. (2009). Identifying and Teaching Children and Young People with Dyslexia and Literacy Difficulties. Report to the Secretary of State for Children, Schools and Families. Retrieved from http://www.education. gov.uk/publications.

Shaywitz, B. A., Shaywitz, S. E., Blachman, B. A., Pugh, K. R., Fulbright, R., K., Skudlarski, P., et al. (2004). Development of left occipitotemporal systems for skilled reading in children after a phonologicallybased intervention. Biological Psychiatry, 55, 926-933.

Shaywitz, S. E., \& Shaywitz, B. A. (2008). Paying attention to reading: The neurobiology of reading and dyslexia. Development and Psychopathology, 20(Special Issue 4), 1329-1349.

Torgesen JK., Wagner, RK., Rashotte, CA., Rose, E., Lindamood, P \& Conway, T. (1999). Preventing rea- ding failure in young children with phonological processing disabilities: Group and individual responses to instruction. Journal of Educational Psychology, 91, 579-593.

Torgesen, J. K., Alexander, A. W., Wagner, R. K., Rashotte, C. A., Voeller, K., Conway, T. et al. (2001). Intensive remedial instruction for children with severe reading disabilities: Immediate and long-term outcomes from two instructional approaches. Journal of Learning Disabilities, 34, 33-58.

Wechsler, D. (2005). Escalas de inteligencia Wechsler IV. Madrid: TEA.

Wolf, M. (2008). Cómo aprendemos a leer. Barcelona: ediciones B.

\section{Evaluación, diagnóstico e intervención en la dislexia}

Resumen. En los últimos años, el aprendizaje de la lectura y sus dificultades ha sido de gran interés para los educadores e investigadores propiciando una evolución en el conocimiento de los procesos implícitos en su aprendizaje. Se ha llegado a un consenso amplio y generalizado acerca de qué es la dislexia y a reconocer las dificultades para adquirir la conciencia fonológica como uno de los predictores más fiables del mismo trastorno.

En Cataluña, a partir de la LEC (2009), se han estimulado las actuaciones en el sistema educativo para garantizar la atención a los trastornos de aprendizaje; en concreto, se ha mejorado la formación de los docentes y se han elaborado instrumentos y materiales que faciliten su tarea, como los protocolos de detección y atención al alumnado con dislexia elaborados en 2011. El presente artículo se centra en este marco y pretende un doble objetivo: (a) orientar y analizar el proceso de actuación más eficiente a la hora de evaluar y diagnosticar precozmente la dislexia, y (b) dar un modelo para que, desde el marco escolar, se puedan asumir competencias y generar procedimientos para garantizar la trayectoria académica de los niños disléxicos y evitar problemas de desajuste emocional y social con el paso del tiempo.

Palabras Clave: dislexia, conciencia fonológica, trastorno de aprendizaje, comorbilidad 